ARCHIVO ESPAÑOL DE ARTE, LXXXVII, 347

JULIO-SEPTIEMBRE 2014, pp. 297-304

ISSN: 0004-0428, eISSN: 1988-8511

doi: $10.3989 /$ aearte.2014.19

\title{
VARIA
}

\section{VELÁZQUEZ Y LAS “CORRALIZAS” DE LA CALLE DEL OLIVAR}

\author{
Álvaro Piedra Adarves
}

\begin{abstract}
En las siguientes páginas se relata la historia de la compra y adquisición por Diego Velázquez de varios terrenos en la madrileña calle del Olivar.

Palabras clave: Diego Velázquez; Diego Pérez Mejía; Calle del Olivar; Censo.

VELÁZQUEZ AND THE “CORRALIZAS” ON CALLE DEL OLIVAR

The author relates the purchase by Diego Velázquez of various plots of land on Madrid's calle del Olivar (Olive Grove Street).

Key words: Diego Velázquez; Diego Pérez Mejía; calle del Olivar (Olive Grove Street); Census.
\end{abstract}

A pesar de la documentación, numerosa, que conservamos sobre Velázquez muchos son los aspectos de su vida y su obra que siguen encerrando paradójicamente puntos oscuros a la investigación. Quizá, uno de estos puntos sea la adquisición por Velázquez de unos terrenos en la madrileña calle del Olivar, barrio de Lavapiés. Ignoramos cual fue el móvil que llevó al pintor a comprar estos solares considerados en aquel momento como unos "eriales" aunque la localización de nuevos documentos permiten hoy reconstruir la historia de esta adquisición comprendida inicialmente por tres terrenos.

En 1991 Cruz Valdovinos dio a conocer la pertenencia de estas propiedades a través de una referencia indirecta en una escritura de dote otorgada en 1648 por un vecino suyo propietario: Francisco de Ortegón. El otorgante declaraba que había recibido por parte de su mujer, Manuela García, unas casas que estaban situadas en la calle del Olivar "esquina a la calle de San Carlos... que...se sirve con puerta que está frente de las corralizas...que bajan...por la calle del Olivar [y] que son de Diego Velázquez"1. Posteriormente, en 1998 se divulgaron otros documentos ${ }^{2}$ que permitieron conocer la adjudicación de uno de estos terrenos ${ }^{3}$.

${ }^{1}$ Cruz Valdovinos, 1991: 95 y 107; 2011: 138 y 241. El documento lleva fecha del 16 de agosto. Ortegón era confitero y criado del rey en la guardia española.

2 ATERIDo FernándeZ, 1998: 293.

${ }^{3}$ La documentación completa sobre Velázquez hasta ese momento se recoge en Corpus Velazqueño, 2000. Véase vol. 1, documentos: 142, 213 y 220, por donde se citan a continuación. 
La historia comienza en 1639 cuando Velázquez compró como "inversión" un censo de 100 ducados al tratante Diego de Muga. El censo estaba impuesto sobre un terreno en la calle del Olivar propiedad entonces del platero Francisco de Garay ${ }^{4}$. La calidad del terreno calificado en aquel momento como un erial "desmantelado" y su mala conservación con una casa en ruinas hizo que el tratante no diese valor al censo y se le traspasase a Velázquez por una cantidad testimonial de 60 ducados. Además, Muga le cedía todos los derechos sobre los réditos acumulados que el platero había dejado de pagar. Con esta venta y traspaso el tratante confesaba que se había librado de un censo improductivo por el que nadie quiso dar "maravedis alguno"s.

Muga, en realidad, evitaba con la pérdida de sus derechos la ejecución de los bienes del platero. Razón por la cual nadie quiso comprar el censo. Velázquez, haciendo gala de su flema, siguió sin cobrar los réditos hasta que en 1647 demandó a Garay por los atrasos de "nueve años y dos tercios" cuantificados en 223 reales y tres cuartillos, a la par que reclamó los réditos caídos anteriores a su compra, décimas y costas. Dichas cantidades es probable que estuvieran controladas por Velázquez a través de un libro básico en aquel momento: la "Arithmetica" de Juan Pérez Moya con "unas tablas para averiguar con facilidad las cuentas de los réditos de los censos,

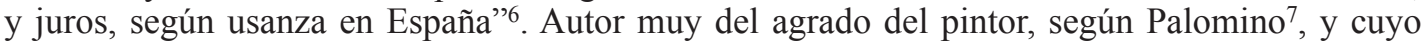
libro formaba parte, al parecer, de su biblioteca ${ }^{8}$.

La sentencia -como es lógico- fue favorable al artista y se remató en una cantidad superior al valor inicial del propio censo por lo que el platero, viejo, pobre y embargado, llegó a un acuerdo con el sevillano para que la ejecución de la sentencia sólo se limitase a la "dejación" del solar. Dejación que fue aceptada "amistosamente" por el pintor bajo escritura del 14 de febrero de $1648^{9}$. Velázquez, independientemente de su acción, ganaba así un terreno por vía judicial a través de los réditos impagados de un censo ${ }^{10}$.

Pero en el ínterin el pintor ya había puesto los ojos (o se los pusieron) en un solar de la misma manzana. Un colega suyo: Diego Pérez Mejía, viejo conocido del sevillano ${ }^{11}$, poseía precisamente un terreno colindante al del platero. Velázquez, al poco de adquirir el censo de Muga, compró a su colega el 26 de junio de 1641 dicho terreno por 450 ducados ${ }^{12}$. Lo más sorprendente de aquel solar es que también era un "muladar" y se había adquirido por Pérez Mejía siguiendo la vía judicial que Velázquez emplearía años después para conseguir el del platero. En esta ocasión, su colega había comprado en 1625 dos censos perpetuos por 46.696 maravedís los

${ }^{4}$ El censo que adquiere es el "consignativo" o también llamado censo "al quitar". Era redimible y se obtenía a través de un préstamo de capital (el principal) gravado a un determinado interés (generalmente al 5\%) bajo el aval de un terreno e inmueble.

5 Corpus Velazqueño, documento 142: 135-136.

${ }^{6}$ Pérez de Moya, 1582: 174-175.

7 Palomino III, 1988: 210. Véase también la edición crítica de la vida de Velázquez por Morán Turina, 2008

${ }^{8}$ El inventario de sus libros recoge una "Arismetica de Moya" (Corpus Velazqueño, documento 436: 479). Sobre la biblioteca de Velázquez véanse los estudios de SÁNCHEz CANTÓN "La librería de Velázquez” y "Los libros españoles que poseyó Velázquez" recogidos en Escritos sobre Velázquez, 2000: 25-52; 175-186. El historiador MorÁN TURINA (2008: 73, nota 59) propone también otras "Aritméticas" de Moya bajo este mismo título.

9 Corpus Velazqueño, documento 213: 187-188.

10 La sentencia era habitual en la época cuando un censatario se declaraba insolvente: el bien gravado se subastaba públicamente (aunque no solían presentarse postores a este tipo de subastas), pasando entonces a poder del censualista.

11 Diego tuvo una hija, Victoria Mejía, que casó con el pintor Andrés Brizuela, un aprendiz de Velázquez entre 1626 y 1629. CRUZ VALDOVINOS ha planteado que este discípulo pudo tener conocimientos pictóricos antes de entrar en el taller del sevillano (1991: 99-101; 2011: 70-71). A este respecto, es probable que Brizuela aprendiese los rudimentos con su suegro continuándolos después con Velázquez. En cuanto al pintor Pérez Mejía, su personalidad está hoy por definir. Se tienen referencias de varios encargos pictóricos significativos: la pintura de un retablo para Madridejos y una serie de doce lienzos con los meses del año (Martín OrTega, 1990: 8v y 296v).

12 Archivo Histórico de Protocolos de Madrid (AHPM), Protocolo 6931: 555-561v. 
cuales estaban impuestos sobre estos suelos, entonces dos parcelas independientes de la calle del Olivar ${ }^{13}$. El fallecimiento de sus propietarios ${ }^{14}$ y la inhibición por parte de sus herederos a la hora de pagar las cargas gravadas hizo que Pérez Mejía les entablase un pleito por réditos impagados que abarcaron "nueve años y dos tercios", exactamente como los reclamó Velázquez. Una vez ganado el pleito Mejía solicitó por vía judicial el dominio directo de esos terrenos, pues el útil ya le tenía, obteniéndoles en $1631^{15}$.

Tras estos datos parece claro que Velázquez no compró el censo a Muga con la intención de hacer una inversión periódica - como se ha señalado- complementaria a sus sueldos "reales". Su bajísimo interés (cercano al 2\%) y los impagos del platero, reincidentes y bien subrayados en la escritura, demuestran que la inversión se enfocó de otra manera y que sus hipotéticos réditos de haberse cobrado no hubieran supuesto apenas ganancias en una economía como la de Velázquez en aquellos años. Sus ingresos como pintor y "criado" del rey le hubieran permitido comprar un censo seguro de mayor cuantía e interés ${ }^{16}$. Si es probable, por el contrario, que Velázquez conociera la experiencia de Pérez Mejía, acaso su inductor en estas compras, y arguyera que por 60 ducados (casi la mitad del valor inicial del censo) podría adquirir con el tiempo un terreno. Una idea que permite comprender la valoración positiva que tuvo que hacer el pintor a la hora de invertir en ese censo y que prueba su aquiescencia cuando renunció a otros bienes embargados del platero pues sólo le interesaba el terreno. Así, el proyecto debió tomar cuerpo cuando compró el solar a su colega. Ahora bien ¿con qué finalidad?

Es obvio que Velázquez debió tener algún propósito con esta compra. Quizá, la inversión a largo plazo de unos suelos sin más ${ }^{17}$. Una inversión poco arriesgada y comedida pero que permite conocer lo saneado de sus finanzas en 1641 pues la compra de los terrenos se concertó con un anticipo de 2.134 reales y unos cómodos plazos de $200 \mathrm{al} \mathrm{mes}{ }^{18}$. Plazos que suponían una cantidad aceptable en aquel momento pero que no debieron asfixiar la economía familiar.

Es posible, tal vez, que quisiera continuar con un proyecto de Pérez Mejía quien tras unificar sus dos solares levantó en ellos unos cimientos con la pretensión de construir una casa ${ }^{19}$. Hipótesis sumamente atractiva que podría conducirnos a la faceta de Velázquez como arquitecto pero

13 El tipo de censo adquirido por Mejía es el reservativo o enfitéutico. Se trata de una forma de venta o cesión del dominio útil de la propiedad a través de una renta anual (generalmente baja) en función del valor de esa propiedad.

14 Se consignan como "herederos de Sebastián Mateos Alcaller" y "Diego López, albañil", respectivamente.

15 El día que Mejía vendió estos suelos a Velázquez le hizo entrega de más de trece títulos y documentos notariales con las ventas y cesiones judiciales de sus antiguos propietarios (véase nota 18). Entre ellos se incluyó una renuncia de dos censos que le hizo una acreedora, Ana de Morales. Estos dos censos (uno por cada terreno de entonces) formaron parte de un lote de tres siendo el tercero el que compró Velázquez en 1639. Ana de Morales era hija y heredera de Gabriel Morales, casado con Ana Sanz de la Monja, mujer en segundas nupcias de Diego de Muga, el tratante. La escritura de venta censal a Velázquez hace hincapié precisamente a que el terreno del platero "es uno de los tres solares que Baltasar de Hermosilla (el fundador de los tres)...dio a censo". Velázquez por tanto tenía un claro conocimiento de las circunstancias del lote completo cuando compró el censo.

${ }^{16}$ Es cierto que el cobro de sus sueldos "reales" se demoraba con frecuencia, a veces durante años, pero la multiplicidad de ellos y sobre todo la precisión con que el sevillano atinó a la hora de reclamarlos al monarca harían que éste no tuviese nunca excesivos problemas de liquidez. Tampoco hay que olvidar sus ganancias externas por pinturas para nobles y funcionarios palaciegos, bien pagadas y apenas consideradas en el cómputo de sus finanzas madrileñas en estos años. BARTOLOMÉ BENASSAR ha realizado un revelador informe sobre el estatus económico del pintor (2012: 64-65, 90-91,102-104).

17 Se sabe que en el año 1628 Velázquez vendió en Sevilla a través de Pacheco un inmueble dotal que había quedado en mal estado tras unas inundaciones. La conservación del solar devaluado no interesó al pintor en esta ocasión (Varia Velazqueña, 1960. Volumen II: 228, nota 2).

18 AHPM, Protocolo, 3804: 175-176v. La fecha de la escritura es de 26 de junio. Recuérdese que su salario como pintor era de 20 ducados al mes (220 reales)

19 Protocolo citado, 6931: 558v

Arch. esp. arte, LXXXVII, 347, JULIO-SEPTIEMBRE 2014, 297-304

ISSN: 0004-0428, eISSN: 1988-8511, doi: 10.3989/aearte.2014.19 
que no se respalda con la documentación conservada sobre él ${ }^{20}$. En 1648, siete años después de haber comprado los terrenos a su colega, las propiedades seguían siendo unas "corralizas" según la declaración de su vecino Ortegón ${ }^{21}$. Ese mismo año, tal como se ha señalado, el pintor adquirió el erial del platero haciéndole dueño del esquinazo completo de una manzana. Si Velázquez tuvo en aquel último momento algún planteamiento sobre el uso de estos suelos, su partida a Italia unos meses después volvería a dejarle sin efecto. A su regreso a España, en junio de 1651, el horizonte y las circunstancias del pintor eran ya otras. La hipotética idea de una residencia familiar en un barrio de baja representatividad, como el de Lavapiés ${ }^{22}$, se desvanece frente a una carrera palatina en ascenso que continuó con el nombramiento como "Aposentador" de Palacio en 1652 y con un aposento real, muy cerca del rey, en la Casa del Tesoro desde al menos 1655.

Se ignora si el pintor obtuvo algún beneficio con estos terrenos. Lo cierto es que el solar procedente del platero debió mantenerse independiente del otro "doble" de Pérez Mejía. El 25 de abril de 1656 se mandó hacer un traslado de la escritura del terreno de Garay (hemos de suponer que lo mandó el pintor) aunque no se sabe con qué motivo ${ }^{23}$. Quizá Velázquez decidiera desprenderse de él. O de los dos. El no conocer el testamento y la partición de los bienes del pintor ha impedido saber si a su muerte era todavía dueño de ellos.

En todo caso, la descripción y los lindes referidos en la escritura de venta del terreno de Pérez Mejía permite precisar hoy su localización, y por ende el de Garay. El documento refiere que el solar:

hace esquina a la calle de San Carlos que atraviesa desde la calle del Ave María a la calle Real de Lavapiés...que entrando en el dicho solar linda por mano derecha que es por la dicha calle de San Carlos y por las espaldas con suelos y casas de Pedro Sánchez De Cos, regidor que fue de esta y por mano izquierda que es por la dicha calle del Olivar con casas de Francisco Garay, platero, que al presente están caídas ${ }^{24}$.

La consulta de la Planimetría General de Madrid realizada en 1751, a pesar de la distancia cronológica con respecto a nuestro pintor, permite situar empero los terrenos con total precisión en la manzana 44 (fig. 1), solares 1 (correspondiente a Pérez Mejía) y 2 (correspondiente a Garay) (fig. 2). Por desgracia, el nombre de Velázquez no es consignado entre sus antiguos propietarios pues se dice que éstos pertenecieron a Juan García Barba, el cual privilegió sus casas en 1708. A pesar de ello, los "Asientos" de las parcelas adjuntas que van de la 27 a la 30, es decir, a las espaldas de la 1 y 2 , refieren que sus propietarios fueron los herederos del regidor Pedro Sánchez de $\operatorname{Cos}^{25}$.

${ }^{20}$ El domicilio del pintor, a la sazón estabilizado, había sido itinerante desde su llegada a Madrid en 1623. Tras un alojamiento eventual en la calle de San Bernardo (1624) pasó a una vivienda en la calle Convalecientes (1625), obteniendo en 1625 una "casa de aposento" situada en la calle Concepción Jerónima. Sin embargo, no parece que esta casa fuese su domicilio en un primer momento pues a su regreso de Italia, en 1631, arrendó un "cuarto" situado en la parroquia de Santiago. El traslado a la calle de la Concepción Jerónima debió efectuarse hacia 1634-1635 realizándose allí diversas obras en 1637. Nada impide pensar que el pintor tuviese la idea quimérica de una casa diseñada por él como vivienda familiar avivada por la compra de los terrenos.

${ }^{21}$ Corpus Velazqueño,2000, documento 220: 192

22 Se ha seguido la clasificación aportada en El Madrid de Velázquez y Calderón. Vidaurre Jofre, 2000: 112-114. Lavapiés era por aquel entonces un barrio muy popular que debía gran parte de su animación a una taberna situada en las casas de Manuela, mujer de Ortegón, frente a las propiedades de Velázquez.

${ }^{23}$ El dato consta en una anotación al margen de la escritura de cesión del terreno de Garay. No se transcribe en Corpus Velazqueño. AHPM, Protocolo. 7630:104.

${ }^{24}$ Protocolo citado 6931: 558v-559. Se describe también con toda puntualidad las medidas del terreno que sumaban un total de 4.917 pies superficiales. El solar era ligeramente más pequeño que el de Garay.

25 Planimetría General de Madrid. 1988, Manzana 44. Los primeros intentos por ubicar estos terrenos a través de la Planimetría se debieron a CruZ VAldovinos quien no pudo precisar su situación por falta de datos (1991: 95). Posteriormente, ATERIDO FERNÁNDEZ (1998: 293) con algo más de información logró determinar la manzana pero no las 


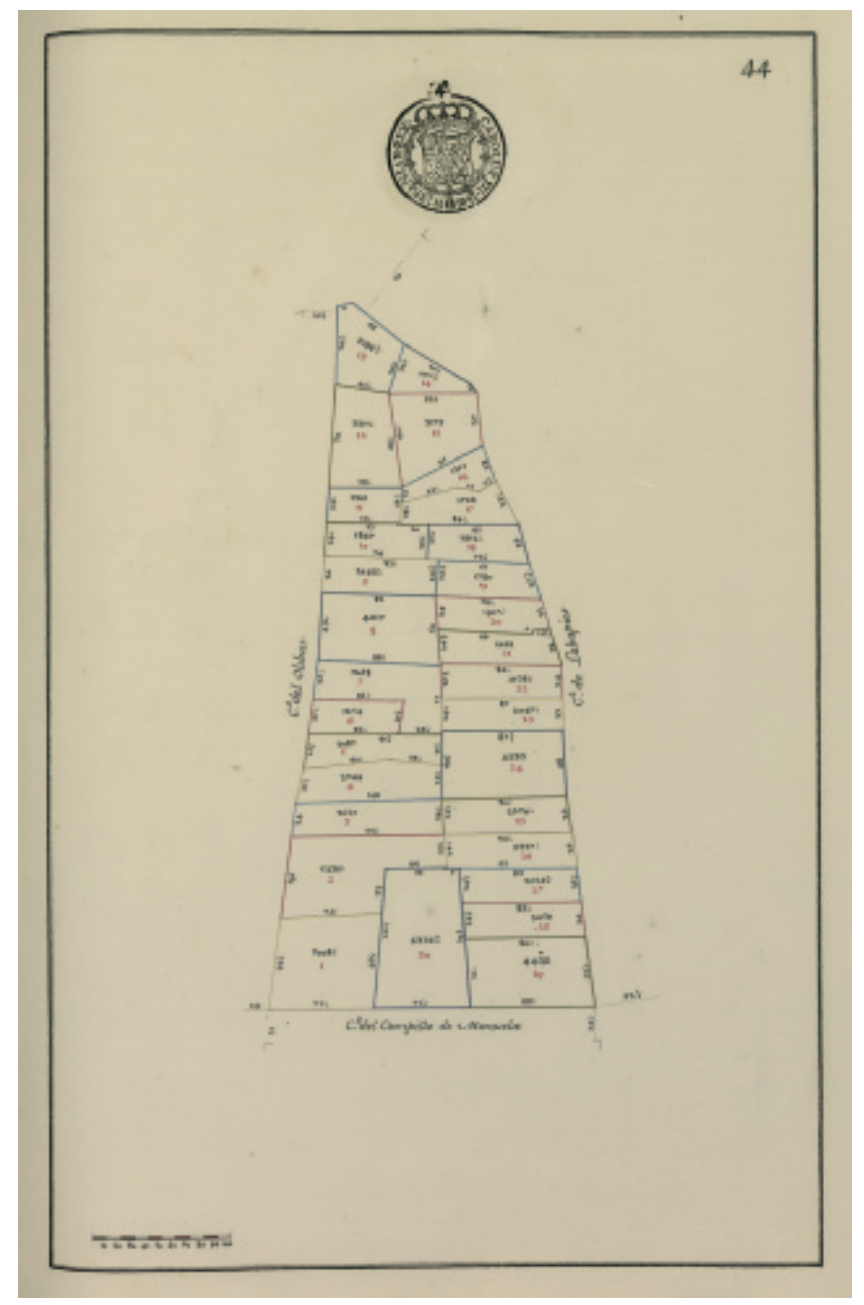

Fig. 1. Planimetría General de Madrid, 1750. Manzana 44. Biblioteca Nacional. Madrid.

El hecho de que la titularidad de Velázquez se perdiera tan pronto en el tiempo podría indicarnos que el pintor mantuvo yermos estos terrenos, y que las primeras casas privilegiadas tras las "arruinadas" fueron precisamente las de García Barba, propietario en lote de las dos parcelas, todavía independientes" ${ }^{26}$.

parcelas. Se ha consultado también el manuscrito "Libro de los nombres y calles de Madrid sobre que se paga incómodos y tercias partes con abecedario" comenzado en 1625 (Biblioteca Nacional, Manuscrito 5918) con la intención de completar la información sobre los propietarios de las casas. En el apartado "Vuelve a la Calle del Olivar" en el fol. 87 se registra "Una casa de Diego Pérez Mejía que fue de Blas Jiménez tasada con 21 ducados con puerta" y en el fol. 88: "Una casa de Francisco García que fue de Baltasar de Acosta en 9 ducados". Este último registro refleja un error del escribiente al transcribir "García" por "Garay". La casa del platero, según indica la escritura de venta censal a Velázquez, había pertenecido previamente a Baltasar de Acosta, portugués.

${ }^{26}$ Una con entrada por Campillo de Manuela (tramo continuo de la calle de San Carlos) y otra por Olivar. 


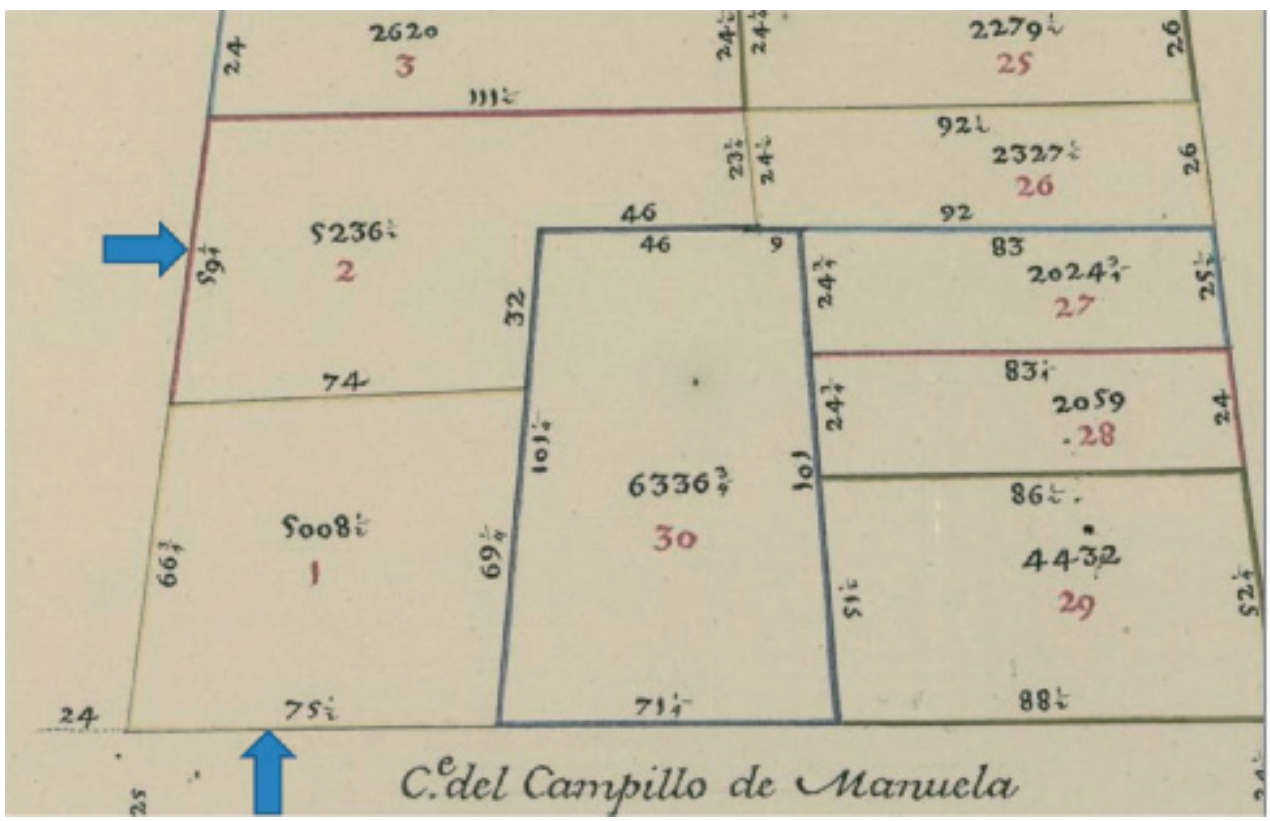

Fig. 2. Planimetría General de Madrid, 1750. Detalle de los Solares 1 y 2 pertenecientes a Velázquez. Biblioteca Nacional. Madrid.

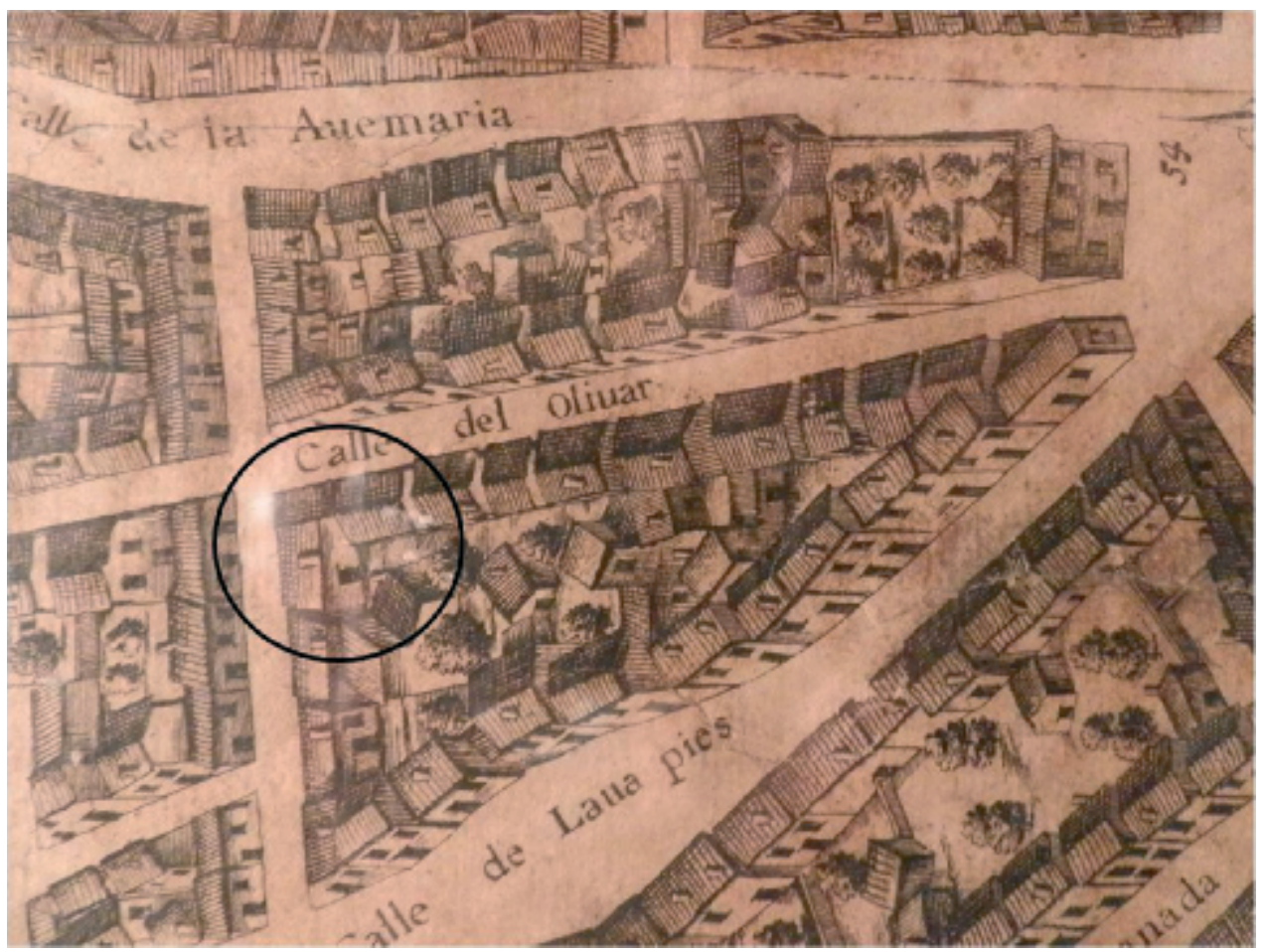

Fig. 3 Plano de Texeira, 1656. Detalle.

Arch. esp. arte, LXXXVII, 347, JULIO-SEPTIEMBRE 2014, 297-304 ISSN: 0004-0428, eISSN: 1988-8511, doi: 10.3989/aearte.2014.19 
El aspecto de la manzana que ofrece el plano de Texeira, grabado en 1656, y por tanto estricto contemporáneo de Velázquez, muestra sin embargo una vista "ideal" de las parcelas con sus casas perfectamente alzadas (fig. 3). ¿Llegó pues Velázquez a emplear estos suelos? ¿Pudo doblar su inversión en caso de venta?

\section{BIBLIOGRAFÍA}

Aterido Fernández, Ángel, "La 'trastienda' del genio: Velázquez y su familia en la década de 1640”, Archivo Español de Arte (AEA), n. ${ }^{\circ} 283,1998$, pp. 289-298 (293).

Benassar, Bartolomé, Velázquez. Vida, Cátedra, Madrid, 2012.

Corpus Velazqueño. Documentos y textos, 2 vols. Ministerio de Educación y Cultura, Madrid, 2000.

Cruz Valdovinos, José Manuel, "Aposento, alquileres, alcabalas, aprendices y privilegios (varios documentos y un par de retratos velazqueños inéditos)", en Velázquez y el arte de su tiempo, V Jornadas de Arte. Madrid, 1991, pp. 91-108.

Cruz Valdovinos, José Manuel, Velázquez. Vida y obra de un pintor cortesano, Caja Inmaculada, Zaragoza, 2011.

Martín Ortega, Alejandro, Notas tomadas por don Alejandro Martín Ortega de escrituras del Archivo Histórico de Protocolos de Madrid. AHPM, Tomo III. Madrid, 1990.

Morán Turina, Miguel, Antonio A. Palomino. Vida de don Diego Velázquez de Silva,

Akal, Fuentes de Arte, núm. 24, Madrid 2008.

Palomino de Castro y Velasco, Antonio, El Museo Pictórico y Escala Óptica con el

Parnaso Español Pintoresco Laureado (Madrid, 1715-1724). Edición Aguilar, Madrid, 1988. Tomo III.

Pérez de Moya, Juan, Arithmetica de Moya, intitulada manual de contadores, Alcalá,

1582.

Planimetría General de Madrid. Planos y Asientos. Edición Facsímil, Tabapress, 2 vols. Madrid, 1988.

Sánchez Cantón, Francisco Javier, Escritos sobre Velázquez, Museo de Pontevedra,

2000.

Varia Velazqueña, Madrid, Ministerio de Educación, 1960. 2 vols.

Vidaurre Jofre, Julio en El Madrid de Velázquez y Calderón. Villa y Corte en el siglo XVII. Volumen II. El plano de Texeira: lugares, nombres y sociedad. Ayuntamiento de Madrid, 2000.

Fecha de recepción: 12-VI-2013

Fecha de aceptación: 5-III-2014

Arch. esp. arte, LXXXVII, 347, JULIO-SEPTIEMBRE 2014, 297-304

ISSN: 0004-0428, eISSN: 1988-8511, doi: 10.3989/aearte.2014.19 